\title{
OPERATIONAL CONTROL OF EFFICIENT AND EFFECTIVE TREATMENT OF COAL BED USING COMPLEX ACTION TAKING INTO ACCOUNT RESONANT NATURAL FREQUENCIES OF THE BLOCK
}

\author{
M. Pavlenko*
}

\begin{abstract}
The article discusses the use of vibrational effects on low-permeability coal seam, with the purpose of increasing the artificial systems of cracks, which ultimately helps to increase gas recovery from solid. Method of vibration exposure tested from underground workings in the coal seam at the mine and is a new and effective way of creating new systems conductive gas cracks. The results of empirical calculations and industrial experiments confirm the possibility of applying this method for increasing the permeability of low-permeability coal. The development of the technological scheme of vibration exposure in the coal massif in the region of the resonant frequencies of the manifold for forming a gas-bearing coal formation limit destructive voltages, creating a vast and uniform zone of artificial fractures in the array and reducing its stress state and gas content is an important actual task.
\end{abstract}

Keywords: vibration, capillary, crack, degassing, installation, impregnation, diameter, methane, liquid, movement, methane, safety, array

\section{Introduction}

The purpose of this article is to study the influence of vibration exposure on the substantiation of technological solutions for the efficient preparation of gas-bearing coal seams in intensive and safe development and management of its properties and the stress-deformed condition to increase fracture permeability and gas recovery from coal.

The idea of using vibration exposure in low-permeability gas-saturated coal massif originated in connection with the low permeability of the coal and, accordingly, a low gas recovery coal, so the paper describes the use of vibration exposure stimulation in the region of the resonant frequencies in a coal seam for the formation of gas-bearing coal formation limit destructive stresses, creating a vast and uniform zone of artificial fractures in the array (Pavlenko 1999, 2002).

The findings are based on a practical experiment on vibration effects of underground mining evaluation of simulation results of field experiments, developed the principles and recommendations for early preparation of the coal seam. The results obtained are used for preparation of the project industrial experiment at a coal mine with the aim of developing and further development of this method in coal mines. Knowing the conditions and parameters of influence on the coal array to increase the fracture, we can predict an increase in metanode for safe exploitation of coal deposits.

\section{Technological solution}

The Method of evaluating the potential of the wave process for large-scale application for the intensive degassing and methane recovery and definition of boundary criteria is based on analysis of mining and geological characteristics of coal deposits; development of technologies for vibration and experience of 
extracting methane from coal seams; economic feasibility, the practical needs of production and utilization of methane.

The method of evaluating the potential of the wave process for large-scale application for the intensive degassing and methane recovery and definition of boundary criteria is based on analysis of mining and geological characteristics of coal deposits; development of technologies for vibration and experience of extracting methane from coal seams; economic feasibility, the practical needs of production and utilization of methane.

To solve this problem, it is proposed to use the developed complex method of vibration action on the coal gas saturated array in order to increase its fracture to intensify the gas separation from the coal array and its subsequent removal by degassing to reduce the concentration of methane in the atmosphere of workings. This effect in combination with hydraulic impact allows to increase the load on the stope on the gas factor and to ensure the safety of mining operations.

These considerations led to the recognition of the vibration effect as a mandatory element of the complex action to ensure fracture and filtration flows in the coal blocks of coal seams.

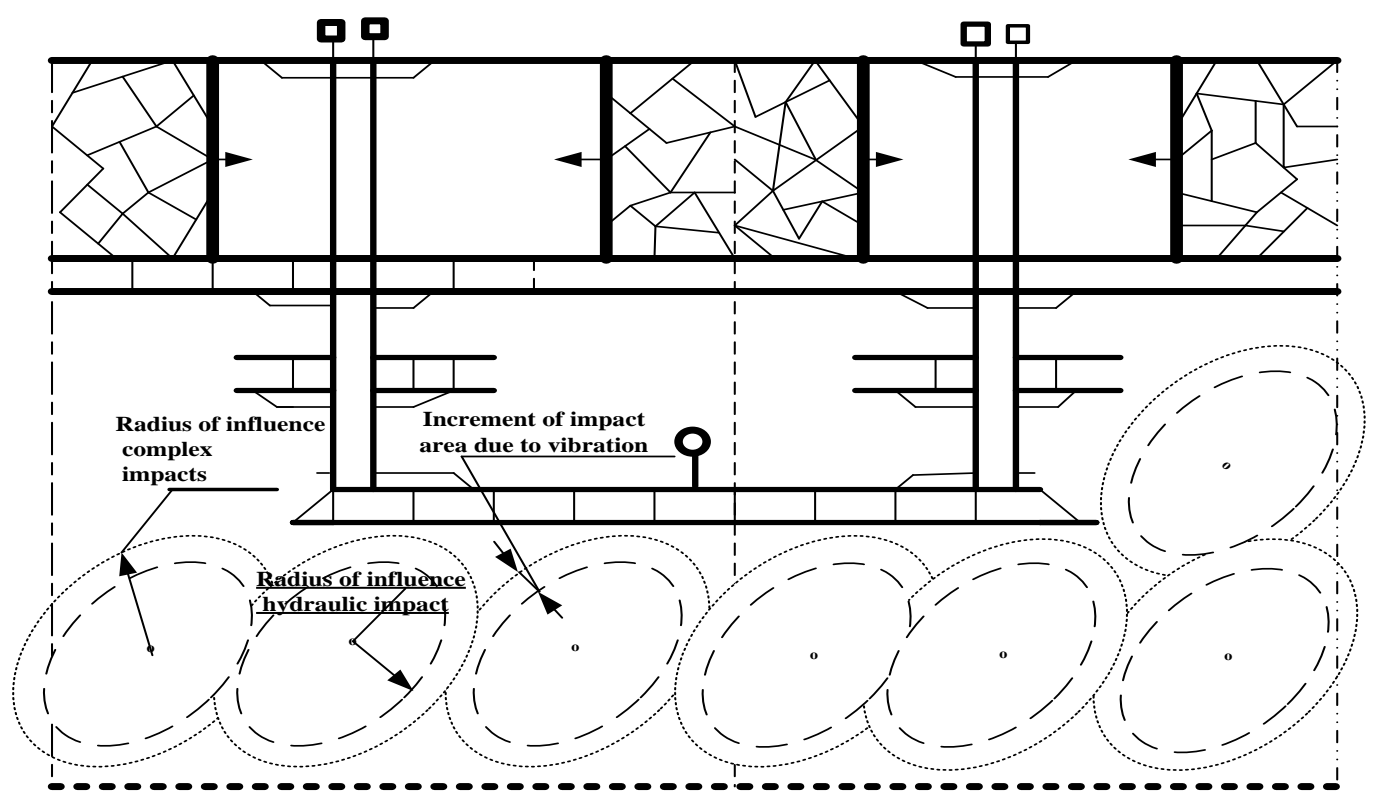

Fig. 1: Technology complex impact on the coal seam in the panel and method of preparation of the reservoir

Fig. 1 presents the integrated effects technology for the coal seam in the panel and method of preparation of the reservoir, while performing hydrofracturing through wells from the surface at the initial stage of impact with further vibration exposure.

It is recommended to perform hydrofracturing with the preset parameters of pressure in the range $\mathrm{R}=25.0$ To $23.0 \mathrm{MPa}$ and the rate of discharge $\mathrm{q}=25.0-45.0 \mathrm{l} / \mathrm{s}$ taking into account the previously carried out works through the well from the surface, the values of the radii of the major and minor axes of the ellipse are in the range of 70-140 meters in the direction of the main system of fissures.

The distance between the holes may be circle of $1.2 \mathrm{R}$ and $0.82 \mathrm{R}$ of the circle. The size of the untreated area of the site is less than 15 meters.

The development of high-performance low-permeability gas-bearing coal seams without the use of special measures to reduce the release of methane from developed coal beds is not feasible.

The natural porosity of the same coal seam at the same the depth varies slightly and ceteris paribus almost constant. However, the value of the natural permeability of fossil coals are dependent on many factors, for different coal seams and enclosing rocks is different, so it varies widely and is usually $0.1-0.001 \mathrm{mD}$.

To reduce the content of methane in low permeability coal seam can then change its properties and state of coal by means of complex effects, defined as geological so mining - technical conditions. 
In this case, low-permeability coal seam is considered as an active medium. Under the active environment will be to understand the environment, reacting to external stimuli. Such environments include coal seams that are in the process of mining.

In the continuous system of reservoir development wells are drilled from the haulage drift of the producing formation (Fig. 1) on the contiguous layer in the zone of the discharge from the rock pressure.

When the development system long poles along strike, when the drifts after the passage of lava are repaid, the wells drilled towards the movement of lava at an angle to the axis of the output.

It is established that at frequencies coinciding with the frequencies of a coal seam close to resonance with the oscillations of the walls of the crack block of the array can be substantial and contribute to the intensification of filtration of cracks and increase of gas reservoirs in the development of coal deposits.

\section{Analytical solution}

Vibration impacts extend a considerable distance from the well to the coal bed. Deformations in a coal seam at vibration influence happen longitudinal, transverse and shear, are characterized by deformations in an array of alternating compression and tension, and also are connected with deformation of shift (are characteristic for a firm phase since for liquids and gases resistance to shift does not exist) (Savelyev, 1970; Nikolaev, 1970).

In them, the movement of particles occur unevenly and in different directions, depending on the pitch.

On the site of complex impact for rocks and coal bed, if the coefficients are known, it is possible to estimate the Young modulus and Poisson's ratio (Savelyev, 1970)

$$
V_{p}=\frac{\sqrt{3(1-v)}}{\beta \delta(1+v)} \text { - (longitudinal) }
$$

where $\beta$ - coefficient of compressibility, $\delta$ - density

$$
V_{s}=\frac{\sqrt{3(1-2 v)}}{2 \beta \delta(1+v)}=\sqrt{G / \delta} \quad \text { - (cross) }
$$

where $\mathrm{G}$ - the shear modulus, $\delta$ - density.

Both types of waves propagate throughout the volume of the low-permeable layer and are therefore considered volumetric. In addition to volume waves, there are waves associated with the surfaces of the formation and lateral rocks-these are surface waves. The wave propagation velocity depends on the elastic properties of the coal gas-saturated formation.

The elastic properties of the formation depend on the porosity coefficient, as well as on the velocity in rocks such as sandstone, limestone, etc. The low permeable coal bed, which is affected by vibration, has its own frequency, which has minimal absorption coefficients (Pavlenko and Vorobyov, 2010; Nikolaev, 1989).

On frequencies: 3-5, 14-15, 25-30 Hz - arises effective energy impact on Plast. This energy is transferred into the depths of the coal massif.

Technological scheme of complex preparation of gas-bearing coal bed is a generalizing effect parameter, which ultimately determines the safety and efficiency of mining operations. Therefore, in the General form of a set of possible variants of the technological scheme of the complex impact, a final scheme of the impact on the coal massif is formed by changing its individual elements. The use of this method in terms of efficiency, having a low energy consumption, which ultimately allows the removal of the gas barrier, leads to an increase in the load on the lava and eliminates the increase in the cost of ventilation (Pavlenko, 2009).

The use of vibration reduces the need for degassing coal seams developed as a way to reduce the concentration of methane. At the same time on different layers intensity of allocation of gas is various that is defined by a mode of conducting mining operations, gas content of the coal massif. Therefore, in this situation it is necessary to achieve such conditions to minimize the inflow of methane into the mining industry. 


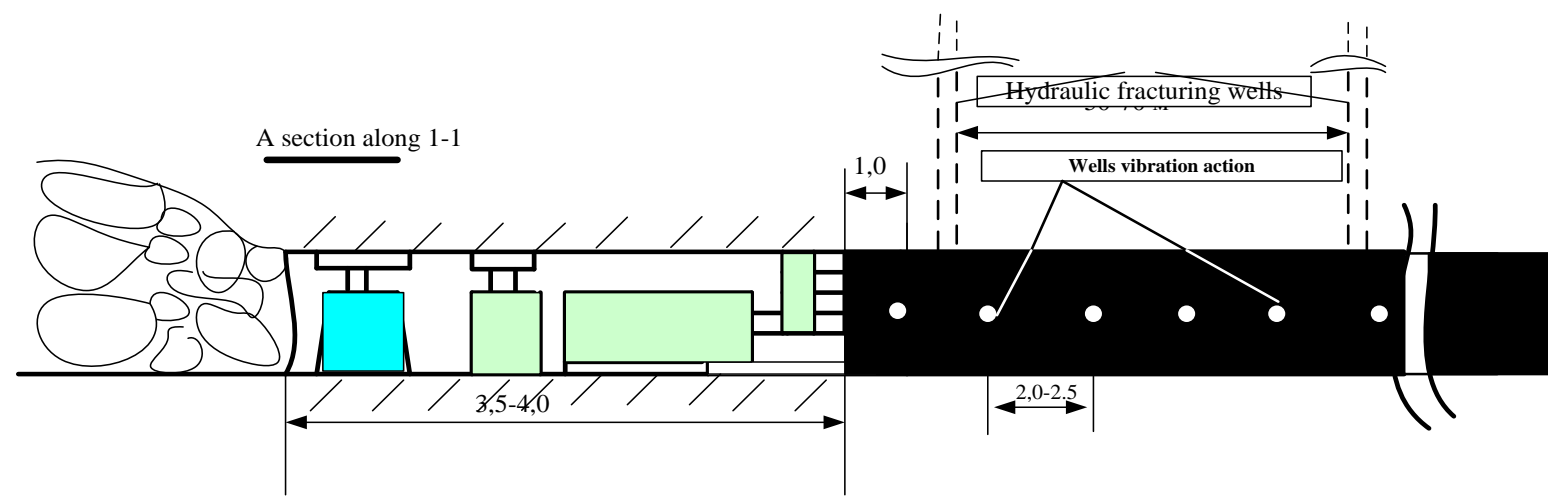

Fig. 2: Cross-section of lava with the use of vibroseis stimulation on the line 1-1

Existing measures to prepare coal seams for safe and effective dredging are not always capable of fulfilling their tasks. When performing complex actions at the stage of well preparation with full reliability, conditions are created that ensure the minimum permissible methane content in the mine workings (Fig. 2).

\section{Results and discussion}

Justified method of complex impact - hydro-vibration effect into low-permeability coal seam, the essence of which is that the processing of the layer produced in two stages, continuously following each other. The first stage creates a network of large cracks in the blocks of the formation (in the process of hydraulic fracturing), the second - (in the process of vibration) creates a system of additional small cracks by branching large cracks formed at the first stage of impact on the formation.

A method of vibration action on the formation of underground workings, the essence of which is that the wells of vibration action are drilled from underground preparatory workings through a rock stopper on the coal bed. Processing of the reservoir produced through the cased section of the wellbore of vibroseis stimulation calculated lengths (3-5 meters). After the works on the vibration of the coal array with a delay of 2-3 days produce work for the drilling and connection of reservoir degassing wells (Pavlenko, 2002).

\section{References}

Nikolaev V.N. (1987) Mechanics of fractured-porous media. Nedra.

Nikolaev V.N. (1989) The mechanism of vibroseis stimulation on oil recovery from fields and the dominant frequency. Proc. USSR Academy of Sciences, Vol 307, No. 3, pp. 570-575.

Pavlenko M.V. (1999) Characteristics of methane release from coal using wave action. Sat. Trudy inst. «Modern problems of coal mine methane», Moscow state mining University, pp. 203-205.

Pavlenko M.V. (2002) Vibration impact on low-permeability gas-bearing the coal seams. Mining information and analytical Bulletin, Moscow state mining University, p. 1-54

Pavlenko M.V. (2009) Vibration impact on coal bed. Mining information and analytical Bulletin, Mountain book. No. 9, pp. 77-79

Pavlenko M.V. and Vorobyov A.N. (2010) Determination of natural frequencies of reservoir fluctuations (mathematical model). Mining information and analytical Bulletin. Moscow state mining University. No 5, pp. 142-144.

Savelyev I.V. (1970) General physics course. Volume 1. Mechanics, vibrations, waves. Moscow: science Publishing house. 